\title{
Water-perfused high-resolution anorectal manometry (HRAM-WP): the first Brazilian study
}

\author{
Ricardo Guilherme VIEBIG ${ }^{1,2}$, Janaina Tomiye Yamakata FRANCO ${ }^{2}$, Sergio Viebig ARAUJO2 and \\ Daniel GUALBERTO ${ }^{3}$
}

\begin{abstract}
Background - High resolution anorectal manometry (HRAM-WP) allows more simplified, objective, and uniform data acquisition and interpretation of the test results. Objective - To validate a HRAM under water perfusion (Alacer Biomédica) with a 24-channel probe and to compare the results of anorectal manometry with other systems. Methods - Individuals without critical evacuation disorders were selected. Patients with incontinence, anal surgery, dyssynergia or sphincter injury were excluded. The test was performed with an Alacer Biomédica 24 channel manometry system under water perfusion, with a probe configured with 6 levels of 4 radial channels, separated from each other by $0.8 \mathrm{~mm}$. The mean pressures for the functional channel were determined, in states of rest (RMP), contention effort (CMP) and evacuation effort (EEMP). The pressure extension of the sphincter was also tabulated in $\mathrm{cm}$. The results were compared with those available in recent literature. Results - Fifty patients were studied (20 men; 30 women). Overall, the following results were obtained: the RMP was $76.9 \pm 3.0 \mathrm{mmHg}$, the CMP was 194.2 $\pm 9.4 \mathrm{mmHg}$, and EEMP was $88.2 \pm 3.7$ $\mathrm{mmHg}$. When classified according to the gender, for men: RMP was $72.2 \pm 3.0 \mathrm{mmHg}$, CMP was $229.5 \pm 17 \mathrm{mmHg}$, and EEMP was $91.4 \pm 7.0$. For women, RMP was $79.8 \pm 4.0 \mathrm{mmHg}$, CMP was $170.7 \pm 8$, and EEMP was $86.1 \pm 4.3 \mathrm{mmHg}$. The sphincter gauge extension for both genders was $3.1 \pm 0.09$ $\mathrm{cm}$ (men 3.3 \pm 0.1 ; women 3.0 \pm 0.1 ). Discussion - Studying HRAM-WP has become much easier. Non-mobilization of the sensor causes less discomfort and artefacts with a lower assessment time. In this study, small differential values between both sexes during rest were observed, highlighting a greater containment force in men. No difference in sphincter extension was noted. The results of this study are consistent with that of existing reports and with those obtained using solid state probes. Conclusion - The perfusion system yielded results similar to that of solid state systems. Further studies to evaluate parameters with respect to pelvic dyssynergia and incontinence need to be conducted. Additionally, to determine if the vector volume can furnish new information in terms of functional and anatomical aspects.
\end{abstract}

HEADINGS - Anal canal, anatomy \& histology. Manometry, trends. Infusion pumps.

\section{INTRODUCTION}

In the last three decades, anorectal manometry has been used routinely to qualify and quantify evacuation disorders. Due to the large variety of protocols, systems, and probes, a comparison between studies has been very difficult ${ }^{(1,2)}$. Since the emergence of high resolution anorectal manometry (HRAM), the equipment and probes are similar in their general configuration as well as the implementation protocols of examination and interpretation of the results. The objectives of the exam remain the same; however, their interpretation have been simplified and have become more practical $^{(3)}$.

There are currently two systems in practice: those that use solid-state probes and those with continuous perfusion. The first system has a high cost and its probes have an uncertain validity, as they are fragile and undergo wear due to reuse and sterilization. High resolution esophageal manometry using perfusion probes, is already routinely used in esophageal exams. Besides lower cost, good sensitivity, and durability, they also give similar results as that of solid state systems ${ }^{(4,5)}$. Conventional systems for anorectal manometry using eight infusion channels have individualized channel distribution configurations along the probe, arranged spirally, or radially with single-line orifices each with $45^{\circ}$ covering the entire circumference. Both system have advantages and disadvantages. In the helical or spiral type, the channels are separated by 0.5 to 1 $\mathrm{cm}$, but do not capture the pressures at the same time throughout the circumference. In radially-disposed probes, the circumference is well represented, but the probe must be mobilized during the examination, which may produce artefacts because it is dependent on the skill of the operator. With the routine use of high-resolution perfusion manometry for the esophagus, a 24-channel anorectal manometry probe was proposed to integrate two main data: observe the anal sphincter in total extension and at circumferential gauge measurement, with dispense of the mobilization during the examination, approaching what is performed by solid state manometry.

Thus, the objective of this study was to validate a 24-channel high resolution perfusion system produced in Brazil, using the commonly described implementation protocols and to compare results already published on similar high-resolution anorectal manometry techniques, regardless of the system used.

Declared conflict of interest of all authors: none

Disclosure of funding: no funding received

${ }^{1}$ Instituto Brasileiro de Estudos e Pesquisas de Gastroenterologia e Outras Especialidades (IBEPEGE), São Paulo, SP, Brasil. ${ }^{2}$ Motilidade Digestiva e Neurogastroenterologia (MoDiNe), São Paulo, SP, Brasil. ${ }^{3}$ Alacer Biomédica Indústria Eletrônica, São Paulo, SP, Brasil.

Corresponding author: Ricardo Guilherme Viebig. Orcid: 0000-0002-6541-0401. E-mail: rviebig@gmail.com 


\section{METHODS}

Fifty individuals of both sexes without critical evacuation disorders, who underwent HRAM-WP were retrospectively selected from a group consisting of approximately 500 patients. Individuals younger than 18 or older than 70 years, those who expressed some degree of incontinence, had pelvic dyssynergia, previous anal surgery, and patients with prior anal injuries were excluded.

The 24-channel Multiplex (Alacer Biomédica, São Paulo, Brazil) was used in this study. The main characteristics of this system are continuous capillary perfusion coupled with a piezoelectric pressure sensor. Continuous capillary perfusion was controlled by a patented original peristaltic pump (Alacer Biomedica), which maintains continuous water flow of $0.6 \mathrm{~mL}$ per minute. The probe is made of polyvinyl chloride (PVC) $4.7 \mathrm{~mm}$ in diameter with six groups of four channels arranged radially at $90^{\circ}$, spaced $0.8 \mathrm{~cm}$ apart from a central channel that communicates with a latex balloon adapted at its end (FIGURE 1).
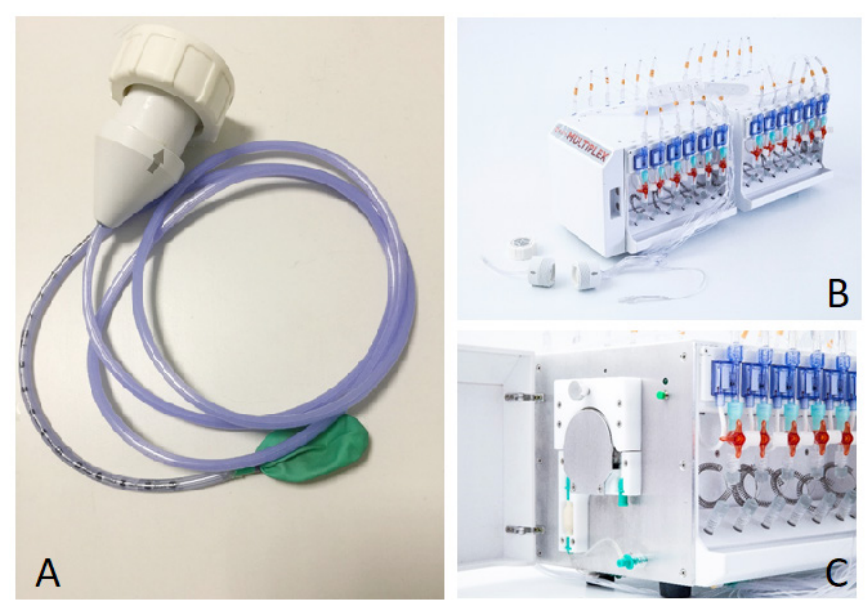

FIGURE 1. A) Manometric probe. B) 24 channels water perfused system (Alacer Biomédica). C) Perfusion pump.

After an interview and explanation of the exam, the patient remained in the left lateral decubitus position and the system was reset to atmospheric pressure at the midline of the buttocks. Once lubricated with gel, the probe was inserted gently until the numerical margin approached the anal margin.

The examination protocol, adapted from Rao et al. ${ }^{(6)}$ was used as follows: accommodation of the probe for two minutes; recording of two minutes at rest pressures; pressure extension of the anal canal characterization; anorectal reflex test; sensitivity tests and rectal capacity test; containment and evacuation effort tests and finally, containment holding time test.

The parameters defined for analysis include the mean rest pressure (RMP) of the anal canal measured at the sphincter extension for 30 seconds. We characterized the sphincter extension as having an isobaric contour with pressures greater than $10 \mathrm{mmHg}$ above rectal pressure (FIGURE 2). The inhibitory anorectal reflex was assumed to be present after gradual air insufflations in increments of $10 \mathrm{~mL}$ in a rectal balloon corresponding to the sphincter pressure drops of at least $20 \%$ relative to rest. Sensitivity and capacity tests were performed with gradual inflations of air in the rectal balloon in $20 \mathrm{~mL}$ increments, taking three manifestations by the patient:

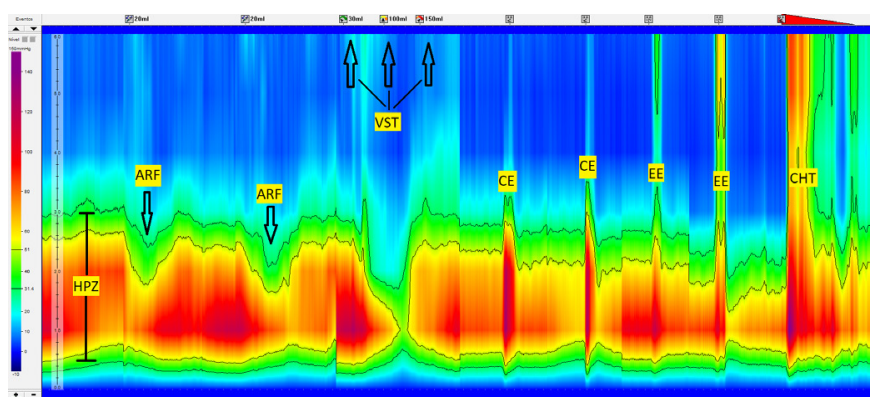

FIGURE 2. Twenty-four channels anorrectal tests graphic. HPZ: high pressure zone; AR: anorrectal reflex; VST: volume sensory test; CE: contention effort; EE: evacuation effort; CHT: containement holding time test.

volumes to trigger the first sensation, the evacuation desire and the evacuation urgency. The pressures during the contention (CMP) and evacuation efforts (EEMP) were obtained by calculating the mean pressure during three seconds of activity for three times, with an interval of 20 seconds between each test. Finally, the containment holding test was performed after the patient was asked to maintain the restraint for a period of 20 seconds while the initial resting pressure was measured, and the mean duration obtained in this time interval was compared. Possible fatigue was determined as the time after which there was a loss of force by $70 \%$ or more from the initial contraction pressure.

The mean rest pressures of the anal canal were analyzed, as well as the gauge length of the sphincter. The mean pressure and the differentials obtained in the contention and evacuation efforts were compared to those at rest. The contention holding time was tabulated for all patients. Finally, the numerical analyses obtained for the rest pressures, contention, and evacuation efforts were compared to the results of studies already published with solid state systems or under water perfusion. The sensitivity and capacity tests were also compared to those published by other authors.

The statistical analyses data of the variables are expressed as mean \pm SEM. The project was approved by the local Ethics Committee under CAAE N: 89325218.5.0000.5450 and all participants signed an informed consent.

\section{RESULTS}

Altogether, 50 subjects ( 20 men and 30 women) were enrolled in the study. The inhibitor anorectal reflex was obtained in all patients after insufflation of air from 20-30 mL. The mean pressure $\pm \mathrm{SEM}$ at rest of the anal canal was $76.9 \pm 3.0 \mathrm{mmHg}$. For women, the values were $79.8 \pm 4.0 \mathrm{mmHg}$ and for men $72.2 \pm 3.0 \mathrm{mmHg}$. The sphincter length measured at rest was $3.15 \pm 0.09 \mathrm{~cm}$ overall, with $3.0 \pm 0.1 \mathrm{~cm}$ for women and $3.3 \pm 0.1 \mathrm{~cm}$ for men. In the contention state, the total pressure of the canal for both genders was $194.2 \pm 9.4$ $\mathrm{mmHg}$, with $170.7 \pm 8.0 \mathrm{mmHg}$ for women and $229.5 \pm 17.0 \mathrm{mmHg}$ for men. In the evacuation effort, the overall pressures measured were $88.2 \pm 3.7 \mathrm{mmHg}$, at $86.1 \pm 4.3 \mathrm{mmHg}$ for women and $91.4 \pm 7.0$ $\mathrm{mmHg}$ for men (TABLE 1).

The time of sustained contraction for 20 seconds were on average above $16.8 \mathrm{~s}$ in women and above $18.8 \mathrm{~s}$ for men $(17.8 \mathrm{~s}$ overall). The results of sensitivity tests and capacity resulted in volumes of air in rectal balloon as follows: for the general group: first sensation $35.8 \pm 2.1 \mathrm{~mL}$, evacuation desire $100.8 \pm 5.6 \mathrm{~mL}$ and urgency to evacuate 164.2 \pm 7.2 $\mathrm{mL}$ (TABLE 1). 
TABLE 1. Values in mmHg obtained of water-perfused high-resolution anorectal manometry in total and in genders.

\begin{tabular}{lccc}
\hline Present study & Total & Female & Male \\
\hline $\mathrm{n}$ & 50 & 30 & 20 \\
Variables & Mean \pm SEM & Mean \pm SEM & Mean \pm SEM \\
Mean resting pressure & $76.9 \pm 3.0$ & $79.8 \pm 4$ & $72.2 \pm 3$ \\
$\begin{array}{l}\text { Maximum squeeze } \\
\text { pressure }\end{array}$ & $194.2 \pm 9.4$ & $170.7 \pm 8$ & $229.5 \pm 17$ \\
$\begin{array}{l}\text { Mean pressure in push } \\
\text { to defecate }\end{array}$ & $88.2 \pm 3.7$ & $86.1 \pm 4.3$ & $91.4 \pm 7$ \\
HPZ length (cm) & $3.1 \pm 0.09$ & $3.0 \pm 0.1$ & $3.3 \pm 0.1$ \\
First sensation (mL) & $35.8 \pm 2.1$ & $31.0 \pm 1.2$ & $43.0 \pm 4.8$ \\
& $100.8 \pm 5.6$ & $100 \pm 7$ & $102 \pm 9.4$ \\
Desire to defecate (mL) & & & $167 \pm 9.8$ \\
Urge to defecate (mL) & $164.2 \pm 7.2$ & $162 \pm 10.9$ & 167 \\
Duration of sustained & 17.8 & 16.8 & 18.8 \\
squeeze (s) & & & \\
\hline
\end{tabular}

SEM: standard error of the mean; HPZ: high-pressure zone.

\section{DISCUSSION}

The MoDiNe is a tertiary center that specializes in instrumental diagnoses of alterations in digestive motility. Anorectal manometry has been performed for over 25 years in a conventional way and as of 6 months ago has aided in the development of a high-resolution perfusion system. Throughout that last 25 years, the published studies presented different results. The main cause of these variances lie in the fact that the methodology in these two decades lacked didactic publications and the protocols were adjusted according to the different centers conducting the exams. Conflicting information further increased the difficulty of understanding, performing and for referring anorectal manometry. Many of these studies contemplated the optics and personal opinions of the authors, making it difficult to reproduce the findings. This made it difficult to accept this simple and valuable diagnostic method to understand altered functional states of pelvic floor function.

With the advent of HRAM-WP, the implementation and analysis of the method was greatly facilitated ${ }^{(7,8)}$. The immobilization of the probe after placement results in reduced discomfort, less presence of artefacts and short study time. The observation of the sphincter circumferentially, including its three-dimensional and volumetric visualization, made the interpretation more intuitive. These facts have helped improve the method in contrast to the conventional system, and recent reports show that the protocols for performing the exam are uniform and the reference values are similar, regardless of the sensor used. Thus, Noelting et al., Li et al. and Carrington et al., reported similar findings in contrast to those in Lee \& Barucha ${ }^{(9,10,11,12)}$. Interestingly, in the latter study, which was conducted in Korea, the general results are not consistent with that of the other authors, with lower values with respect to resting, contention, and effort pressures; although, the study reached the same conclusions with respect to the differences of the mean contention force and resting pressures between the two $\operatorname{sexes}^{(12)}$. This can be explained by the difference in the ethnicity of the participants and the subjectivity that may be related to the protocol of the exam. In a comparative study between the two systems, Rasijeff et al. demonstrated similar numbers for the resting pressure, but it shows higher values for pressures obtained by the solid state method with respect to contention effort, which they suggest maybe attributable to the probe's faster response and sensitivity. In the end, it reviews and compares several publications and recommends that the values of normality should be computed for each system ${ }^{(13)}$. Wang $\mathrm{Al}$ et al., when analyzing 126 volunteers, obtained results equivalent to those of the present study when the values were not classified according to the sex of the participants ${ }^{(14)}$ (TABLE 2).

TABLE 2. Comparative values in $\mathrm{mmHg}$ of water-perfused or solidstate high-resolution manometry for both sex.

\begin{tabular}{lcc}
\hline Authors & Wang $^{(14)}$ & Present study \\
\hline Method & ARM-SS & ARM-WP \\
Variables & Mean \pm SD & Mean \pm SEM \\
$\mathrm{N}$ & 126 & 50 \\
Maximum resting pressure & $79.3 \pm 17.8$ & - \\
Mean resting pressure & $71.8 \pm 17.3$ & $76.9 \pm 3.0$ \\
Maximum squeeze pressure & $178.7 \pm 52.8$ & $194.2 \pm 9.4$ \\
HPZ length (cm) & $3.4 \pm 0.6$ & $3.1 \pm 0.09$ \\
First sensation (mL) & $47.4 \pm 10.0$ & $35.8 \pm 2.1$ \\
Desire to defecate (mL) & $84.5 \pm 18.2$ & $100.8 \pm 5.6$ \\
Urge to defecate (mL) & $125.8 \pm 28.5$ & $164.2 \pm 7.2$ \\
Duration of sustained squeeze (s) & - & 18.8 \\
\hline AR & - &
\end{tabular}

ARM-SS: anorectal manometry solid state; ARM-WP: anorectal manometry water- perfused; SD: standard deviation; SEM: standard error of the mean; HPZ: high-pressure zone.

The participants enrolled in these cited studies vary with respect to the number of participants, their sex, age, and ethnicity, indicating that we should extend the studies to larger and more heterogeneous populations.

The data obtained in this study reinforce the significant discrepancies in the states of rest, containment, and the evacuation effort, considering the mean pressure of the anal canal, as shown in TABLE 1. Men presented much larger contraction pressures in contrast to women, confirming the findings of other authors and previous reports on conventional manometry ${ }^{(8,10,11,12,15)}$.

The comparison with other studies aimed at demonstrating the possibility of performing the same exam in similar protocols by two different systems and to evaluate the differences and similarities in the resultant values, emphasizing that the states of contention and evacuation effort (interdependent operators and patients), may present a greater variability according to the studied population. 
For the resting state, one can observe, according to TABLES 3 and 4 , that the values from several authors and the present study are very similar, increasing our eagerness to establish a standard reference value that represents the normal for humans. A possible limitation of this study may be the selection of patients, as it did not involve healthy volunteers. The patients were selected through the filter of minor indications such as anal pruritus or chronic constipation. Other limitations of this study are common to other reports ${ }^{(10)}$. For example, it is not possible to check structural changes of the sphincters at the time of the procedure by ultrasound or resonance imaging. The requested effort test, both of containment and evacuation, has an important and possible role of subjectivity, since it is dependent on the willingness of the patient and the positive action of the operator, which should be considered when performing comparisons. Manometric studies of incontinence evaluation should be pre-classified by incontinence scales for a better selection and quantification of patients, is the next step in our laboratory. We speculate that in view of the current methodology, with standardization of the exam protocol, there will be greater stimulation for research and ease of comparison. Numerical results should approximate and homogenize the different populations. Clinical applicability and indications will be much more grounded and defined, and the parameters obtained in patients with pelvic dyssynergia may better guide their treatment ${ }^{(13,16-19)}$. This volumetric study (vector volume) can bring new information to the functional and anatomical aspects and prove its usefulness by iconographic representation ${ }^{(20)}$.

\section{CONCLUSION}

There is a significant improvement in the conventional manometry technique to HRAM-WP. The agility and ease of implementation are the most evident highlights. Here, the parameters obtained by the system were evaluated in the states of rest and containment, as well as the manometric extension of the functional anorectal sphincter was measured. The results obtained were closely similar to that obtained using the solid state and continuous perfusion equipment from other manufacturers and the results of several previously published reports.

\section{Authors' contribution}

Viebig RG (MD): preparation of the text, analysis of the tests. Franco JT and Araujo SV: (nurses): perform the examinations, data compilation. Gualberto D (engineer): hardware and software development.

TABLE 3. Comparative values in $\mathrm{mmHg}$ of water-perfused or solid-state high-resolution manometry in men. Adapted from Lee \& Barucha ${ }^{(12)}$.

\begin{tabular}{|c|c|c|c|c|c|c|c|c|c|c|}
\hline Authors & $\begin{array}{l}\text { Present } \\
\text { study }\end{array}$ & \multicolumn{2}{|c|}{ Li et al. ${ }^{(11)}$} & \multicolumn{2}{|c|}{ Lee et al. ${ }^{(12)}$} & $\begin{array}{c}\text { Carrington } \\
\text { et al. }{ }^{\left({ }^{10)}\right.}\end{array}$ & \multicolumn{2}{|c|}{$\begin{array}{l}\text { Cross-Adame } \\
\text { et al. }{ }^{15)}\end{array}$} & $\begin{array}{l}\text { Rasijeff } \\
\text { et al. }{ }^{(13)}\end{array}$ & $\begin{array}{l}\text { Rasijeff } \\
\text { et al. } .^{(13)}\end{array}$ \\
\hline Method & ARM-WP & \multicolumn{2}{|c|}{ ARM-SS } & \multicolumn{2}{|c|}{ ARM-SS } & ARM-SS & \multicolumn{2}{|c|}{ ARM-SS } & ARM-SS & ARM-WP \\
\hline Variables & $\begin{array}{l}\text { Mean } \pm \\
\text { SEM }\end{array}$ & Mean \pm SEM & $95 \% \mathrm{CI}$ & Mean & IQR & Mean \pm SD & Mean & $95 \% \mathrm{CI}$ & $\begin{array}{c}\text { Mean } \\
\text { (5th - 95th } \\
\text { percentile) }\end{array}$ & $\begin{array}{c}\text { Mean } \\
\text { (5th - 95th } \\
\text { percentile) }\end{array}$ \\
\hline $\begin{array}{l}\text { Maximum } \\
\text { resting pressure }\end{array}$ & - & $96.5 \pm 2.2$ & $65.2-73.8$ & - & - & - & 90 & $83-96$ & - & - \\
\hline $\begin{array}{l}\text { Mean resting } \\
\text { pressure }\end{array}$ & $72.2 \pm 3$ & $61.3 \pm 2.1$ & $56.5-65.5$ & 46 & $39-56$ & $73 \pm 23$ & - & - & $71(49-117)$ & $67(340-116)$ \\
\hline $\begin{array}{l}\text { HPZ length } \\
(\mathrm{cm})\end{array}$ & $3.3 \pm 0.1$ & $3.6 \pm 0.1$ & $3.4-3.8$ & - & - & $3.9 \pm 0.8$ & 4.3 & $4.1-4.5$ & - & - \\
\hline $\begin{array}{l}\text { First sensation } \\
(\mathrm{mL})\end{array}$ & $43.0 \pm 4.8$ & $44.2 \pm 1.8$ & $40.6-47.8$ & 10 & $10-20$ & - & 22 & $20-25$ & - & - \\
\hline $\begin{array}{l}\text { Desire to } \\
\text { defecate }(\mathrm{mL})\end{array}$ & $102 \pm 9.4$ & - & - & 80 & $60-120$ & - & 94 & $82-103$ & - & - \\
\hline $\begin{array}{l}\text { Urge to } \\
\text { defecate }(\mathrm{mL})\end{array}$ & $167 \pm 9.8$ & $102.5 \pm 4.1$ & $94.2-110.8$ & 130 & $110-178$ & - & 163 & $140-167$ & - & - \\
\hline $\begin{array}{l}\text { Duration of } \\
\text { sustained } \\
\text { squeeze (s) }\end{array}$ & 18.8 & $12.3 \pm 0.7$ & $10.8-13.8$ & - & - & $16 \pm 11$ & 30 & $28-30$ & - & - \\
\hline
\end{tabular}

ARM-SS: anorectal manometry solid state; ARM-WP: anorectal manometry water- perfused; SD: standard deviation; SEM: standard error of the mean; HPZ: high-pressure zone; CI: confidence interval; IQR: interquartile range. 
TABLE 4. Comparative values in $\mathrm{mmHg}$ of water-perfused or solid-state high-resolution manometry in women. Adapted from Lee \& Barucha ${ }^{(12)}$.

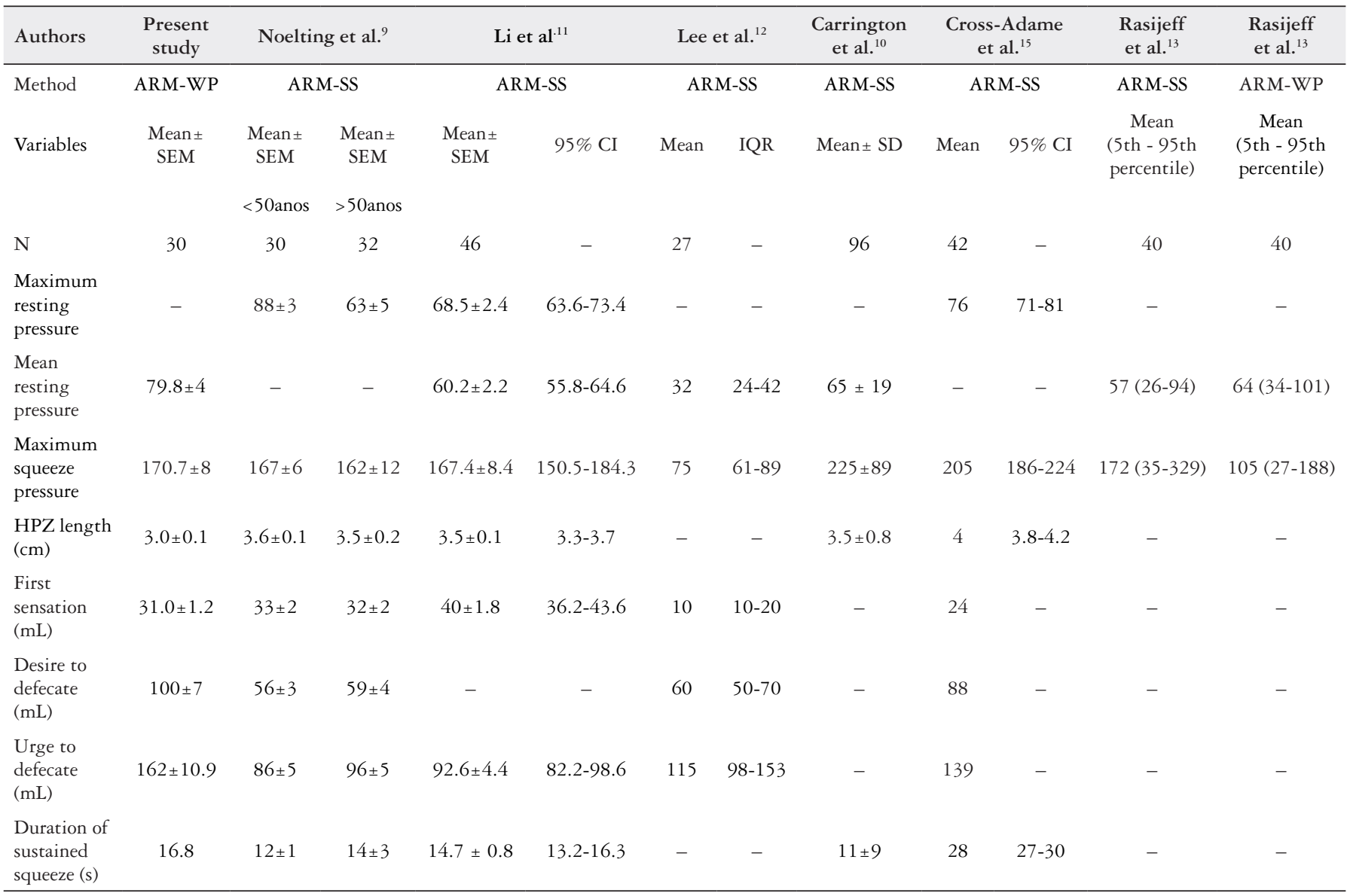

ARM-SS: anorectal manometry solid state; ARM-WP: anorectal manometry water- perfused; SD: standard deviation; SEM: standard error of the mean; HPZ: high-pressure zone; CI: confidence interval; IQR: interquartile range.

Viebig RG, Franco JTY, Araujo SV, Gualberto D. Manometria anorretal de alta resolução sob cateter de perfusão (MARAR): primeira experiência no Brasil. Arq Gastroenterol. 2018. Ahead of print.

RESUMO - Contexto - Através da manometria anorretal de alta resolução (MARAR), a aquisição dos dados e a interpretação do exame tornaram-se mais simplificadas, objetivas e uniformes. Objetivo - Validar um sistema de MARAR sob perfusão de água (Alacer Biomédica), com sonda de 24 canais e comparar resultados dos exames de manometria anorretal com outros sistemas em trabalhos já publicados. Métodos - Selecionados indivíduos sem distúrbio evacuatório importante. Excluídos pacientes com incontinência, cirurgia orificial, dissinergia, ou lesão esfincteriana. O exame foi realizado com sistema Alacer Biomédica de manometria sob perfusão de agua de 24 canais, com sonda configurada com 6 níveis de 4 canais radiais, distanciados entre si por 0,8 mm. Estabelecidas as pressões médias para o canal funcional, nos estados de repouso (PMR), no esforço de contenção (PMC) e no esforço evacuatório (PMEE). Também foi tabulada a extensão pressórica do esfíncter em $\mathrm{cm}$. Comparou-se os resultados com os disponíveis em literatura recente. Resultados - Foram estudados 50 pacientes (20 masc; $30 \mathrm{fem}$ ). No geral, foram encontrados os seguintes resultados: a PMR foi de

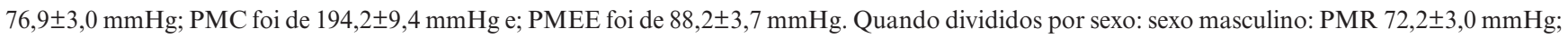

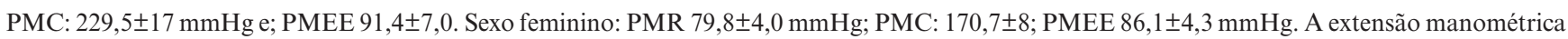
para ambos os sexos foi de $3,1 \pm 0,09 \mathrm{~cm}$ (masc 3,3 $\pm 0,1$; fem $3,0 \pm 0,1$ ). Discussão - A realização do estudo da MARAR ficou muito facilitada. A não mobilização da sonda provoca menos desconforto e artefatos, com menor tempo de estudo. Em nossa série há valores diferenciais pequenos entre os sexos durante o repouso, destacando-se maior força de contenção no sexo masculino. Não houve diferença para a extensão do esfíncter. Em relação à comparação com os estudos já publicados, mesmo com sondas de solid state, há uma proximidade de valores. Conclusão - O sistema de perfusão utilizado permitiu reproduzir resultados similares a sistemas solid state. Resta estabelecer parâmetros em casos de dissinergia pélvica, incontinência e esclarecer se o estudo pelo vetor volume pode trazer novas informações nos aspectos funcional e anatômico.

DESCRITORES - Canal anal, anatomia \& histologia. Manometria, tendências. Bombas de infusão. 


\section{REFERENCES}

1. Carrington EV, Heinrich H, Knowles CH, Rao SS, Fox M, Scott SM. Methods of anorectal manometry vary widely in clinical practice: results from an international survey. Neurogastroenterol Motil. 2017;29:e13016.

2. Simpson RR, Kennedy ML, Nguyen MH, Dinning PG, Lubowski DZ Anal manometry: a comparison of techniques. Dis Colon Rectum. 2006;49: 1033-8.

3. Dinning PG, Carrington EV, Scott SM. The use of colonic and anorectal high-resolution manometry and its place in clinical work and in research. Neurogastroenterol Motil. 2015;27:1693-708.

4. Jones PM, Post J, Crowell MD. High-resolution manometry in the evaluation of anorectal disorders: a simultaneous comparison with water-perfused manometry. Am J Gastroenterol. 2007;102:850-5.

5. Kang HR, Lee JE, Lee JS, Lee TH, Hong SJ, Kim JO, et al. Comparison of high-resolution anorectal manometry with water-perfused anorectal manometry. J Neurogastroenterol Motil. 2015;21:126-32.

6. Rao SS, Azpiroz F, Diament N, Enck P, Tougas G, Wald A. Minimum standarts of anorectal manometry. Neurogastroenterol Motil. 2002;14:553-9.

7. Vitton V, Benezech A, Bouvier M. High-resolution anorectal manometry may probably be worth every penny. Neurogastroenterol Motil. 2018;30(1). doi: 10.1111/nmo.13217

8. Basilisco G, Bharucha AE. High-resolution anorectal manometry: An expensive hobby or worth every penny? Neurogastroenterol Motil. 2017;29(8). doi: 10.1111/ nmo.13125.

9. Noelting J, Ratuapli SK, Bharucha AR, Harvey DM, Ravi K, Zinsmeister AR Normal values for high-resolution anorectal manometry in healthy women: effects of age and significance of rectoanal gradiente. Am J Gastroenterol. 2012;107:1530-6.

10. Carrington EV1, Brokjaer A, Craven H, Zarate N, Horrocks EJ, Palit S, et al. Traditional measures of normal anal sphincter function using high-resolution anorectal manometry (HRAM) in 115 healthy volunteers. Neurogastroenterol. Motil. 2014;26:625-35.
11. Li Y, Yang X, Xu C, Zhang X. Normal values and pressure morphology for three-dimensional high-resolution anorectal manometry of asymptomatic adults: a study im 110 subjects. Int J Colorectal Dis. 2013;28:1161-8.

12. Lee TH, Bharucha AE. How to perform and interpret a high-resolution anorectal manometry test. J Neurogastroenterol Motil. 2016;22:46-59.

13. Rasijeff AMP, Withers M, Burke JM, Jackson W, Scott SM. High-resolution anorectal manometry: a comparison of solid-state and water-perfused catheters. Neurogastroenterol Motil. 2017;29(11). doi: 10.1111/nmo.13124.

14. Wang AJ, Shi YQ, Zheng XL, He XX, Zhou XJ, Li HM, et al. [Normal values for solid state high resolution anorectal manometry in healthy adult volunteers] [Article in Chinese]. Zhonghua Nei Ke Za Zhi. 2017;56:572-6.

15. Cross-Adame E, Rao SS, Valestin J, Ali-Azamar A, Remes-Troche JM. Accuracy and reproducibility of high-resolution anorectal manometry ans pressure topography analyses in healthy subjects. Clin Gastroenterol Hepatol. 2015;13:1143-50.

16. Mion F, Garros A, Brochard C, Vitton V, Ropert A, Bouvier M, et al. 3D High-definition anorectal manometry: Values obtained in asymptomatic volunteers, fecal incontinence and chronic constipation. Results of a prospective multicenter study (NOMAD). Neurogastroenterol Motil. 2017;29(8). doi: 10.1111/nmo.13049.

17. Knowles CH, Rao SS, Fox M, Scott SM; International Anorectal Physiology Working Party Group (IAPWG). Methods of anorectal manometry vary widely in clinical practice: Results from an international survey. Neurogastroenterol Motil. 2017;29(8). doi: 10.1111/nmo.13016.

18. Ding S. [Value of anorectal manometry in defecation disorders and its clinical interpretation]. [Article in Chinese]. Zhonghua Wei Chang Wai Ke Za Zhi. 2016;19:1342-4.

19. Grossi U, Carrington EV, Barucha AE, Horrocks EJ, Scott MS, Knowles CH. Diagnostic accuracy study of anorectal manometry for diagnosis of dyssynergic defaecation. Gut. 2016:65:447-55.

20. Mion F, Garros A, Subtil F, Damon H, Roman S. Anal sphincter function as assessed by $3 \mathrm{D}$ high definition anorectal manometry. Clin Res Hepatol Gastroenterol. 2018. doi: 10.1016/j.clinre.2017.12.004. 